\title{
A tetraferrocenyl-resorcinarene cavitand as redox-switchable host of ammonium salts
}

\author{
Sheila Ruiz-Botella,${ }^{[a]}$ Pietro Vidossich ${ }^{[b]}$ Gregori Ujaque, ${ }^{*[b]}$ Cristian Vicent ${ }^{*[\mathrm{c}]}$ and Eduardo Peris ${ }^{*[a]}$
}

\begin{abstract}
The tetraannulation of a resorcinarene-octaaminocavitand with ferrocene-carboxaldehyde allows the preparation of a tetrabenzimidazole-resorcinarene cavitand with four ferrocenyl moieties directly linked to the $\mathrm{C} 2$ carbon of the imidazoles. The oxidation of the four ferrocenyls produces important structural modifications of the molecule, as indicated by the DFT calculations performed for the neutral and tetra-oxidised forms of the cavitand. By means of ${ }^{1} \mathrm{H}$ NMR spectroscopy, the encapsulating properties of the new tetraferrocenyl-resorcinarene cavitand were evaluated, toward a series of ammonium salts, for which a clear size cutoff in binding affinity was observed. The cyclic voltammetric studies allowed us to estimate the relative association constants for the neutral and oxidized form of the cavitand, indicating that the guest in bound to the neutral (reduced) state of the cavitand, and released from its oxidised form. These redox-addressable conformational and binding properties of the resorcinarene-tetraferrocenyl cavitand, constitute all necessary features of a redox-switchable molecular gripper. By mass spectrometry we were able to unambiguously confirm the molar stoichiometry of the host-guest complex (1:1), and also to assess the strong guest encapsulation, as indicated by triggering the covalent coupling between host and guest in the gas phase.
\end{abstract}

\section{Introduction}

The development of concave bowl- or ring-shaped molecules, or cavitands, which can bind guest molecules by matching size and electrostatic interactions, constitutes the backbone of host-guest chemistry. ${ }^{[1]}$ Cavitands have also been defined as open-ended host molecules with vase-shaped cavities, in which complementary species can be detained. ${ }^{[2]}$ Cavitands of varying depths and physical properties may be readily made through covalent binding of neighboring hydroxyl groups of resorcinareneoctols. Depending on the functionalization of the rim o-phenylene-bridged cavitand, this type of molecules can have a rigidified vase conformation and hinder the release of the guest molecule from the cavity. ${ }^{[2 b]}$ The introduction of metal

[a] Sheila Ruiz-Botella and Eduardo Peris Dpto. de Química Inorgánica y Orgánica Universitat Jaume I

Avda. Sos Baynat. E-12071-Castellón. Spain

Fax: (+) 34964387522

E-maileperis@uji.es

[b] Dr. Pietro Vidossich and Dr. Gregori Ujaque

Departament de Química. Universitat Autónoma de Barcelona

08193-Cerdanyola del Vallès, Catalonia, Spain.

gregori@klingon.uab.es

[c] Dr. Cristian Vicent

'Serveis Centrals d'Instrumentació Científica. Universitat Jaume

Avda. Vicente Sos Baynat. 12071-Castellón. Spain.

barrera@sg.uji.es

Supporting information for this article is given via a link at the end of the document. complexes into the structures of traditional organic cavitands not only offers the possibility to form unique supramolecular architectures, but also provides access to new materials with enhanced metal-based catalytic properties, $\left.{ }^{[1 \mathrm{~b},} 1 \mathrm{e}, 3\right]$ and even afford the construction of stimuli responsive metallosupramolecular architectures for the reversible capture and release of therapeutic guests. ${ }^{[4]}$ Metal fragments may also act as redox centers, and therefore their incorporation at the rim of non-covalently arranged bowl-shaped molecules may serve for modulating the size and shape of the macromolecule by electrochemical stimuli. Organic-based redox switchable cavitands have recently shown exciting properties, since the ability of the supramolecule to open and close can be electrochemically controlled, and in doing so, guest molecules can be dragged or released. ${ }^{[1 \mathrm{c}, 5]}$ Redox-switchable metal-based cavitands have been scarcely studied. Ferrocene may be used as an effective electroactive marker of the complexation of cavitands, because it retains its reversible one-electron redox character, with the possibility of showing substantial redox changes depending on the microenvironment and, in particular, to the presence of guest molecules. ${ }^{[6]}$ Since Beer and coworkers described the first ferrocene-amide receptors for binding and sensing anions, ${ }^{[7]}$ several authors have provided different strategies for introducing ferrocene to the lower and upper rims of calixarenes and resorcinarene, ${ }^{[1 b, 8]}$ and most of these type of sensors were used for the recognition of anions, due to the ability of the oxidized form of ferrocene, ferrocenium, to electrostatically interact with anions. All in all, we found that while most of the works regarding the description of new ferrocene-containing macromolecules were focused on providing effective preparative methodologies, and on the description of the electrochemical properties of the resulting materials, the enormous potential derived from the redox-switchable conformational changes, which can be used to tune the trapping ability of the cavitand remains fundamentally unexplored. Because tetrabenzoimidazole-resorcinarene cavitands are known to be effective receptors for hosting and selectively recognizing small molecules, ${ }^{[9]}$ we thought that marrying these molecules with ferrocenes, may result in unique systems with redox-tunable trapping properties. In this work, we describe the preparation of a ferrocenyl-substituted tetrabenzoimidazole, which forms kinetically stable inclusion complexes with a series of ammonium salts on the NMR timescale. The thermodynamic affinity for a series of ammonium-based molecules is assessed by NMR spectroscopy, as well as by Mass Spectrometry and Cyclic Voltammetry.

\section{Results and Discussion}

The resorcin[4]arenebenzimidazole-ferrocenyl compound 1, was obtained by the tetra-annulation of the related octaamino-based cavitands $^{[10]}$ with ferrocene-carboxaldehyde (Scheme 1). The compound was isolated in high yield (65\%) as an air-stable red 
solid, and was characterized by NMR spectroscopy, ESI mass spectrometry and elemental analysis. The molecule adopts a vase-type conformation in solvents such as $\mathrm{CHCl}_{3}$, benzene, and DMSO, as indicated the representative ${ }^{1} \mathrm{H}$ NMR signal due to the proton at the resorcinarene-methyne group (triplet at 5.1 > $\delta>6.3$, depending on the solvent used). ${ }^{[1 \mathrm{c}, 11]}$

The electrochemical analysis was performed by cyclic voltammetry of $\mathbf{1}$, and revealed a single reversible simultaneous four-electron redox process $\left(\mathrm{E}_{1 / 2}=0.65 \mathrm{~V}\right)$, associated to simultaneous oxidation of the four ferrocenyl fragments, thus implying that they are essentially electronically uncoupled.

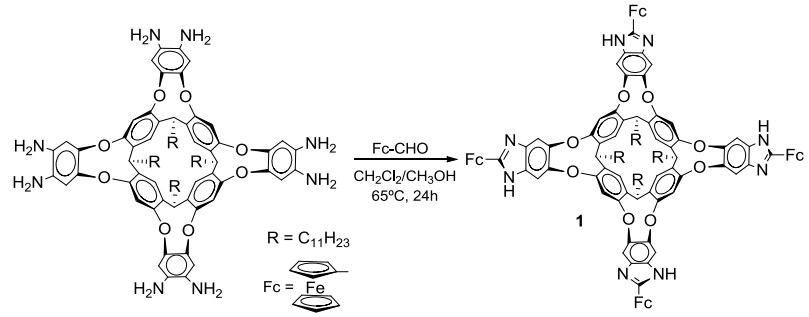

Scheme 1.Synthesis of Cavitand 1

The vase-type conformation of the molecule is also supported by DFT (PBE-D3) calculations, which show that the energyminimized structure of the ferrocene-containing molecule adopts a closed structure with $C_{4}$-symmetry (Figure 1a. For simplification of the calculation, we used $R=M e$, and labelled this new molecule as 2). Interestingly, the four ferrocenyl moieties are partially closing the upper rim of the molecule, therefore forming a top-closed container molecule, rather than an open-ended cavity. The energy difference between the open and closed conformations (vase and kite shapes, respectively) for 2 in solution is $27.5 \mathrm{kcal} / \mathrm{mol}$, favoring the closed (vase) one. In order to determine whether the oxidation of the four ferrocenyl fragments would introduce a significant conformational change in the resulting tetracationic molecule, we also optimized the structure of $\left[2^{4+}\right]\left(\mathrm{Cl}^{-}\right)_{4}$. The oxidized form opens the cavity by the upper rim by separating the arms along with the ferrocenium moieties pointing away of the cavity, but still maintaining the vase conformation of the cavitand. The four chloride ions are alternatively located between the metallic fragments, thus minimizing the electrostatic repulsions of ferrocenium fragments (Figure $1 \mathrm{~b}$ ). The optimization of $\mathbf{2}^{\mathbf{4 +}}$ (without the four chlorides) shows a more expanded conformation (SI, Figure S24), with the four arms of the cavitand leaving a wide open structure. Hence, oxidation of the iron center results in a marked change between open and closed conformations.

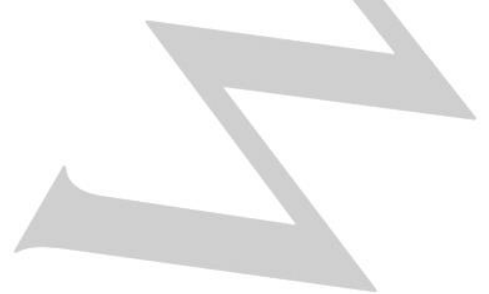

a)

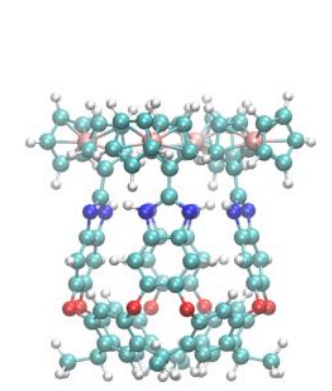

b)
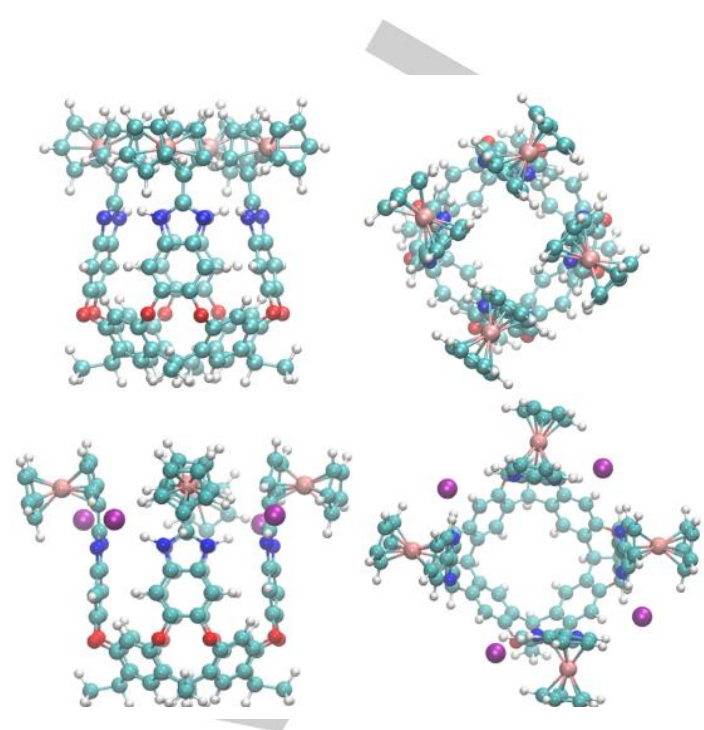

Figure 1. Two perspectives of the energy-minimized geometry at DFT(PBED3) of a) $2(\mathrm{R}=\mathrm{Me})$, and b) $\left[2^{4+}\right]\left(\mathrm{Cl}^{-}\right)_{4}$

Next, we investigated whether the ferrocenyl-footed cavitand $\mathbf{1}$, could serve as a suitable supramolecular host for small organic molecules. In particular, we tested the binding of several tetraalkylammoniums, choline and L-carnitine (Scheme 2) using a variety of solvents. For $\mathrm{CDCl}_{3}$ and $\mathrm{CD}_{2} \mathrm{Cl}_{2}$, encapsulation was evidenced by the characteristic upfield chemical shifts of the alkyl groups of the guest molecules, but signals from both the cavitand 1 and the guests were typically broad, likely due to the operation of intermediate exchange regimen. Under these circumstances, we decided to avoid the use of $\mathrm{CDCl}_{3}$ and $\mathrm{CD}_{2} \mathrm{Cl}_{2}$ for the NMR studies, and used other solvents for which the signals due to the encapsulated molecules provided sharper diagnostic signals. The study of the ${ }^{1} \mathrm{H}$ NMR spectra of equimolecular mixtures of 1 with the guest cations $3^{+}-7^{+}$and 8 in benzene- $d_{6}$ and toluene- $d_{8}$, revealed the formation of kinetically stable host-guest complexes on the ${ }^{1} \mathrm{H}$ NMR timescale. The comparison of the ${ }^{1} \mathrm{H}$ NMR spectra of 1 with equimolecular amounts of the tretraalkylammoniums $3^{+}-5^{+}$, revealed that there is a clear size cutoff for the binding affinities. While tetrabutylammonium $\left(3^{+}\right)$did not show any detectable evidences of binding, tetramethylammoniun chloride revealed a single resonance at $-1.2 \mathrm{ppm}$, which is diagnostic of encapsulation. The association constant was estimated as $260 \mathrm{M}^{-1}$ by integration of the signals due to free and complexed $1 .{ }^{1} \mathrm{H}$ diffusion-ordered NMR spectroscopy (DOSY) revealed that signals from the cavitand and that of $\mathrm{NMe}_{4}{ }^{+}$at $-1.2 \mathrm{ppm}$ diffused with the same rate $\left(D=3.1 \times 10^{-10} \mathrm{~m}^{2} / \mathrm{seg}\right.$, see Figure S24 in the Supplementary Information). ${ }^{[12]}$ Figure 2 shows the representative regions of a series of ${ }^{1} \mathrm{H}$ NMR spectra of 1 with increasing amounts of $\mathrm{NMe}_{4} \mathrm{Cl}$. 


$$
\mathrm{R}^{\mathrm{R}} \stackrel{\overbrace{\mathrm{R}}^{\mathrm{R}}}{\mathrm{R}} \operatorname{\mathrm {Cl}}^{+}
$$

$[3+]\left(\mathrm{Cl}^{-}\right), \mathrm{R}=n \mathrm{Bu}$

$\left[4^{+}\right]\left(\mathrm{Cl}^{-}\right), \mathrm{R}=\mathrm{Et}$

$\left[5^{+}\right]\left(\mathrm{Cl}^{-}\right), \mathrm{R}=\mathrm{Me}$

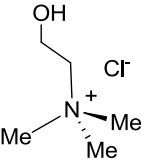

$\left[7^{+}\right]\left(\mathrm{Cl}^{-}\right)$

Choline chloride

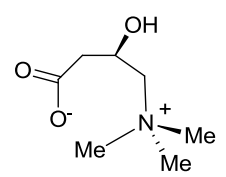

L-Carnitine

Scheme 2. Structures of ammonium guests $3^{+}-7^{+}$and 8

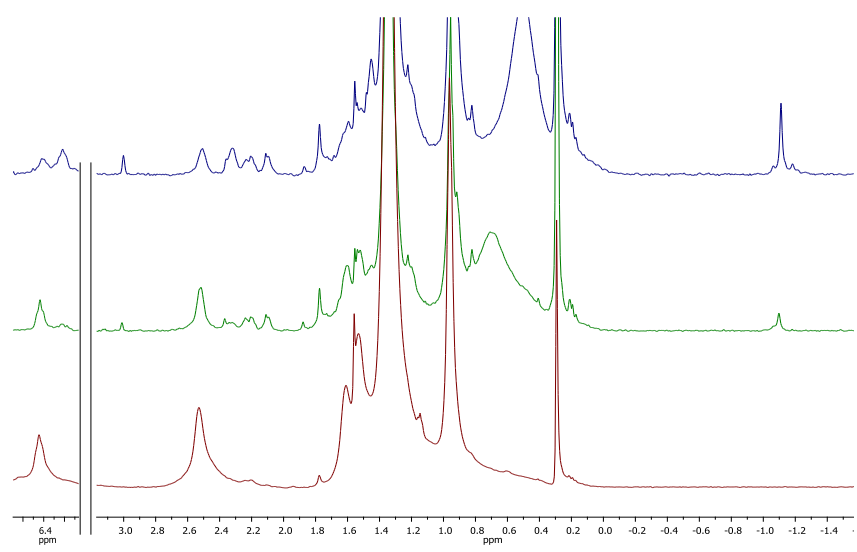

Figure 2. Representative regions of the ${ }^{1} \mathrm{H}$ NMR spectra in $\mathrm{C}_{6} \mathrm{D}_{6}$ of a series of samples containing cavitand 1 with increasing amounts of $\mathrm{NMe}_{4} \mathrm{Cl}$. Concentration of 1: $3.5 \mathrm{mM}$. Concentration of $\mathrm{NMe}_{4} \mathrm{Cl}$, a) $0 \mathrm{mM}$, b) $3.5 \mathrm{mM}$, and c) $7 \mathrm{mM}$. The signal at $6.44 \mathrm{ppm}$ corresponds to the proton at the resorcinarene-methyne group of the uncomplexed cavitand. The signal at 6.31 $\mathrm{ppm}$ corresponds to the resorcinarene-methyne group of the complexed host:guest system. The signal at $-1.2 \mathrm{ppm}$ is assigned to the protons of the methyl group of the encapsulated $\mathrm{NMe}_{4}{ }^{+}$.

Tetraethylammonium $4^{+}$, dodecyltrimethylammonium $6^{+}$and choline $7^{+}$, also formed host-guest complexes with 1 , as observed by the appearance of resonances at $-2.0,-1.61$ and $1.06 \mathrm{ppm}$, respectively. Under the same experimental conditions, L-carnitine did not show any signals that could be assigned to the formation of a host-guest complex, but the addition of tetrabutylammonium chloride to the equimolecular mixture of $\mathbf{1}$ and 8 , resulted in the appearance of a sharp signal at $-0.87 \mathrm{ppm}$, ascribed to the protons of the methyl groups of $\mathbf{8}$. This result is relevant, because it indicates that the presence of the salt is crucial for boosting the binding affinity between the tetraalkylammoniums and $\mathbf{1}$, most likely due the formation of ionpairs within the cavity where either ion- $\pi$ or electrostatic interactions are needed to stabilize the host-guest interactions. This ion-pair encapsulation type has precedent in closely related cavitands decorated with benzylbenzimidazoles. ${ }^{[13]}$ Table 1 shows the association constants for the encapsulation of $4^{+}-7^{+}$ and 8 in $\mathrm{C}_{6} \mathrm{D}_{6}$ and toluene- $d_{8}$.

Table 1. Association constants for tetraalkylammonium salts with 1 . Determined by ${ }^{1} \mathrm{H}$ NMR spectroscopy at $298 \mathrm{~K}$.

\begin{tabular}{lll} 
Guest & Solvent & $K_{\mathrm{a}}\left(\mathrm{M}^{-1}\right)$ \\
\hline $\mathrm{NMe}_{4} \mathrm{Cl},\left[5^{+}\right]\left(\mathrm{Cl}^{-}\right)$ & $\mathrm{C}_{6} \mathrm{D}_{6}$ & 260
\end{tabular}

$\mathrm{NEt}_{4} \mathrm{Cl},\left[4^{+}\right]\left(\mathrm{Cl}^{-}\right)$

$\mathrm{N}\left(\mathrm{C}_{16} \mathrm{H}_{33}\right) \mathrm{Me}_{3} \mathrm{Cl},\left[6^{+}\right]\left(\mathrm{Br}^{-}\right)$

Choline chloride, $\left[7^{+}\right]\left(\mathrm{Cl}^{-}\right)$

Carnitine $^{\mathrm{a}}, \mathbf{8}$

$\mathrm{NMe}_{4} \mathrm{Cl},\left[5^{+}\right]\left(\mathrm{Cl}^{-}\right)$

$\mathrm{NEt}_{4} \mathrm{Cl},\left[\mathbf{4}^{+}\right]\left(\mathrm{Cl}^{-}\right)$

Choline chloride, $\left[7^{+}\right]\left(\mathrm{Cl}^{-}\right)$

Carnitine $^{\mathrm{a}}, \mathbf{8}$

$\mathrm{C}_{6} \mathrm{D}_{6}$

60

500

70

$110^{\mathrm{a}}$

350

Toluene- $d_{8} \quad 130$

Toluene- $d_{8} \quad 30$

Toluene- $d_{8} \quad 70$

${ }^{a}$ In the presence of an excess of $\mathrm{NBu}_{4} \mathrm{Cl}$

The encapsulation abilities of 1 were also investigated by ESI mass spectrometric techniques. ESI-MS-based methods have been previously used to study binding events between resorcinarenes ${ }^{[14]}$ and alkylammonium salts. In the present study, the ESI mass spectra of equimolar mixtures $\left(5 \times 10^{-4} \mathrm{M}\right)$ of 1 and the ammonium guests depicted in Scheme 2 were investigated in $\mathrm{CHCl}_{3}: \mathrm{CH}_{3} \mathrm{OH}$ (1:1). Illustrative ESI mass spectra for the tetramethylammonium guest are shown in Figure 3. Prominent peaks formulated as $[\mathbf{1}+\mathbf{5}]^{+}$and $[\mathbf{1}+\mathbf{5}+2 \mathrm{Cl}]^{-}$in the positive and negative scan modes, respectively, are clearly distinguished, thus confirming the 1:1 stoichiometry of the host-guest complex. For the experiments carried out with the rest of the ammonium salts, we observed the formation of the supramolecular complexes between host 1 and all guests, except for the case of $3^{+}\left(\mathrm{NBu}_{4}^{+}\right)$, for which we did not detect any peak. For L-carnitine, $\mathbf{8}$, the $1: 1$ adduct $[\mathbf{1}+\mathbf{8}+\mathrm{Cl}]^{-}$was observed, whereas for the rest of the cationic guests $4^{+}-7^{+}$, the formation of adducts with $1: 1$ stoichiometry of general formula $[1+\text { guest }+2 \mathrm{Cl}]^{-}$was manifested (Figure S23 in the Supplementary Information shows the ESI-MS spectrum in the negative scan mode of a mixture of 1 and a five-fold excess of $3^{+}-8$ ).
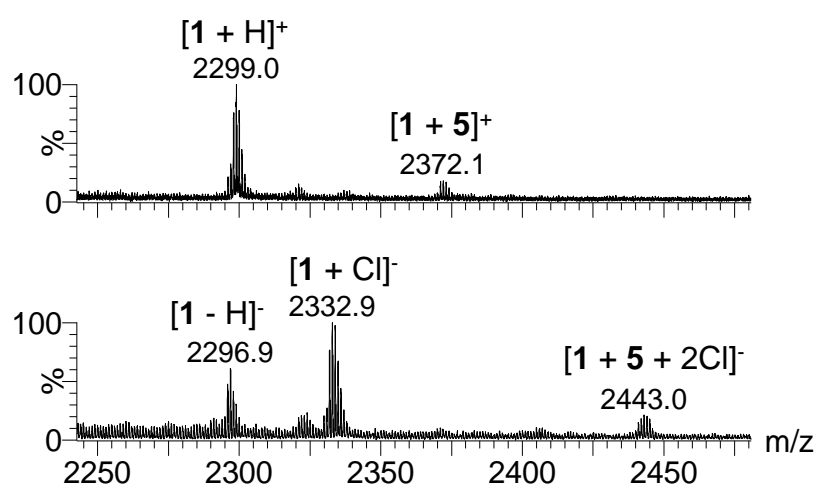

Figure 3. ESI-MS spectra of an equimolar mixture of 1 and $5+$. In the positive (top) and negative (bottom) scan modes.

The gas-phase study of molecular capsules using soft ionization tandem mass spectrometric techniques is known to provide very rich information about structural aspects and intrinsic reactivity 
of the encapsulated guest. ${ }^{[15]}$ Some interesting examples of the use of this technique have already been applied to the cucurbit[n]uril family of molecular containers (either coordination complexes $^{[16]}$ or amino acids $\left.{ }^{[17]}\right)$, for which the possibility of investigating reactions inside molecular containers has been proved. ${ }^{[18]}$ We explored the gas-phase dissociation properties of the supramolecular adducts formed between $\mathbf{1}$ and $\mathbf{3}^{+}-\mathbf{7}^{+}$and $\mathbf{8}$, by collision induced dissociation (CID) experiments. For the supramolecular ions with guests $4^{+}-7^{+}$, namely $[1+$ guest $+2 \mathrm{Cl}]$ (guest $=4^{+}-7^{+}$), the CID mass spectra were similar. As an illustrative example, the fragmentation channels for the encapsulation of $\mathbf{4}^{+}$are depicted in Figure 4 , together with the CID mass spectrum.
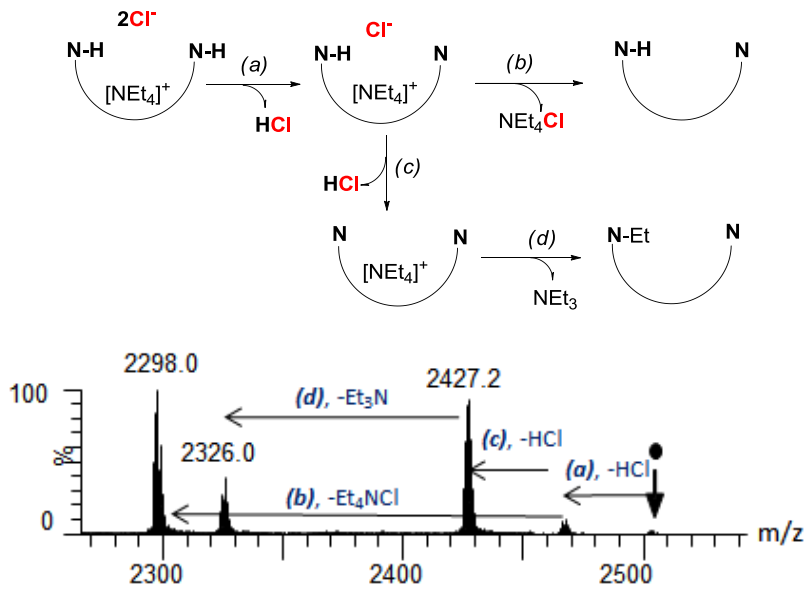

Figure 4. (Top) Schematic representation of the fragmentation channels $a-d$ of the $[1+4+2 \mathrm{CI}]$ adduct. Two $\mathrm{NH}$ groups are schematically drawn in the precursor ion to depict the imidazoles involved in the fragmentation pathway. (Bottom) CID mass spectrum of $[\mathbf{1}+\mathbf{4}+2 \mathrm{CI}]^{-}$.

For $[\mathbf{1}+\mathbf{4}+2 \mathrm{Cl}]$, a first fragmentation channel involves the liberation of $\mathrm{HCl}(a)$. Two competitive steps are then observed upon increasing the collision energy: the expulsion of the ion pair $\mathrm{Et}_{4} \mathrm{NCl}(b)$, which formally leads to [1 - $\left.\mathrm{H}\right]$, and the loss of a second $\mathrm{HCl}$ molecule $(c)$. For channels $a$ and $c$, the release of $\mathrm{HCl}$ most likely involves the loss of the two $\mathrm{NH}$ protons at the imidazoles. The final fragmentation channel (d) corresponds to the liberation of $\mathrm{Et}_{3} \mathrm{~N}$, which implies the cleavage of a $\mathrm{N}-\mathrm{C}$ covalent bond of the $\mathrm{Et}_{4} \mathrm{~N}^{+}$group. It is important to mention that fragmentation channel $d$ is not observed until the two imidazole rings are deprotonated, and for that reason it may be assumed that the $\mathrm{N}-\mathrm{C}$ bond breaking occurs concomitant with the ethylation of the imidazole, as illustrated in Figure 4. Further support to the fragmentation scheme depicted in Figure 4 was provided by "in-source" gas-phase generation of the proposed intermediates and subsequent CID investigation. For example, gas-phase generation of the $[(1-\mathrm{H})+4+\mathrm{Cl}]^{-}$anion at $\mathrm{m} / \mathrm{z}$ 2463.2 was achieved by "in-source" fragmentation of [ $1+4+$ ${ }_{2} \mathrm{CI}^{-}$at higher cone voltages (typically in the range $\mathrm{Uc}=90$ to $100 \mathrm{~V})$. Mass-selection and CID of the $[(\mathbf{1}-\mathrm{H})+\mathbf{4}+\mathrm{Cl}]^{-}$anion evolved $\mathrm{NEt}_{4} \mathrm{Cl}$ (channel b) and $\mathrm{HCl}$ followed by $\mathrm{NEt}_{3}$ (channels $c$ and d). The CID mass spectra of supramolecular adducts of 1 with guests $5^{+}, 6^{+} 7^{+}$and 8 were very similar in terms of the energy-required to trigger fragmentation, as well as for the identity of the fragments evolved. As far as fragmentation channel $d$ is concerned, for all these cations a methyl group was lost, instead of an ethyl group.

Even though gas-phase guest dissociation through covalent or non-covalent bond breaking is well-known, the occurrence of covalent coupling between hosts and guests is unusual in gasphase host-guest chemistry. ${ }^{[19]}$ Cavitand 1 reported herein, displays two important features; first, it enables strong guest encapsulation and, second, it provides reactive walls in the host that trigger the coupling between both entities.

In order to evaluate the potential electrochemical sensing abilities of the ferrocenyl-cavitand 1, voltammetric studies were carried out. For these studies, and for obvious experimental reasons (solubility of the electrolyte, preparation of the solutions under standard CV experimental procedures), the studies were carried out in $\mathrm{CHCl}_{3}$, instead of benzene or toluene which were the solvents of choice for the NMR measurements. The equilibrium between the neutral and oxidized forms of 1 and the guest molecules $(G)$, may be treated by means of the SquareScheme thermodynamic cycle depicted in Scheme $3,{ }^{[20]}$ in which $K_{\text {red }}$ and $K_{\text {ox }}$ represent the association constants for 1 and $1^{4+}$, respectively, and $E_{\mathrm{f}}$ and $E_{\mathrm{c}}$, represent the formal potentials of the free and complexed cavitand, which can be directly determined from the voltammetric responses.

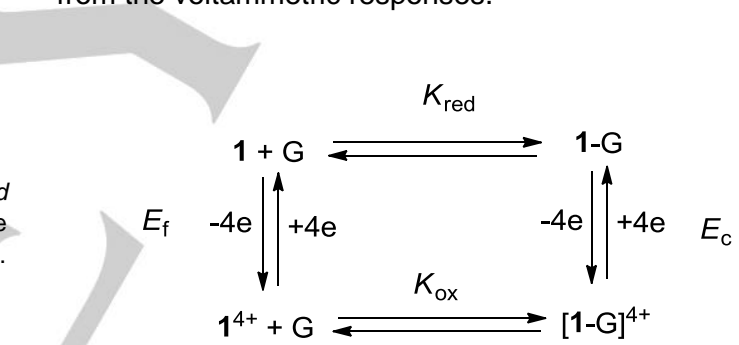

Scheme 3. Square scheme for the equilibrium between the neutral and oxidized forms of 1 , and $\mathrm{G}$ (guest)

The titration of cavitand $\mathbf{1}$ with progressive addition of solutions of guest produced significant anodic perturbations of the ferrocenes' oxidation potentials ( $\Delta E \approx 90-180 \mathrm{mV}$ ), except for the $\mathrm{NBu}_{4} \mathrm{Cl}$ case, for which the shift was negligible (Table 2). This simple observation is interesting, because it indicates that the receptor only gives a response for the cases for which the encapsulation is effective, and that the anodic shifts are due to the encapsulation of the cation, rather than to a process implying the association of the counter-anions with the protons at the rim of the cavitand. The result is also in agreement with the fact that the guest has a cationic nature, and therefore the anodic shift of the oxidation potential may be explained as a consequence of the lower tendency of the ferrocene moieties to be oxidized in a cationic environment. In fact, the reverse effect (a cathodic shift) has been described when anions are encapsulated in other ferrocenyl-containing cavitands. ${ }^{[\mathrm{m}]}$ The positive shift also reveals that the guest has a thermodynamic preference for the neutral host over the tetracationic species $1^{4+}$, as shown by the 
$K_{\text {red }} / K_{\text {ox }}$ ratios, which can be derived from equation 1. In other words, these results support the idea that guests are bound in the reduced (closed) state of the cavitand, and fully released in the oxidized (open) state.

$K_{\text {red }} / K_{o x}=\exp \left(n F \Delta E_{1 / 2} / R T\right)$

Table 2. Electrochemical cation recognition data and association constants with cavitand 1 .

\begin{tabular}{llll} 
Guest & $\begin{array}{l}\Delta E \\
(\mathrm{mV})\end{array}$ & $K_{\text {red }} / K_{\text {ox }}$ & $\begin{array}{l}\Delta G_{\text {red }}-\Delta G_{\text {ox }} \\
(\mathrm{kcal} / \mathrm{mol})\end{array}$ \\
\hline $\mathrm{NMe}_{4} \mathrm{Cl},\left[\mathbf{5}^{+}\right](\mathrm{Cl})$ & 160 & $8.2 \times 10^{10}$ & -14.9 \\
$\mathrm{NEt}{ }_{4} \mathrm{Cl},\left[\mathbf{4}^{+}\right](\mathrm{Cl})$ & 93 & $2.1 \times 10^{6}$ & -8.6 \\
$\mathrm{~N}\left(\mathrm{C}_{16} \mathrm{H}_{33}\right) \mathrm{Me} \mathrm{Ml}_{3} \mathrm{Cl},\left[\mathbf{6}^{+}\right](\mathrm{Cl})$ & 182 & $2.25 \times 10^{12}$ & -16.8 \\
Choline chloride, $\left[7^{+}\right](\mathrm{Cl})$ & 173 & $4.5 \times 10^{11}$ & -15.9 \\
$\mathrm{NBu}{ }_{4} \mathrm{Cl},\left[\mathbf{3}^{+}\right](\mathrm{Cl})$ & 20 & - & --
\end{tabular}

The data potentials were collected by differential pulse voltammetry and cyclic voltammetry using $0.2 \mathrm{mM}$ of compound 1 in $\mathrm{CHCl}_{3}$ in the presence of $0.1 \mathrm{M}$ $\mathrm{NBu}_{4} \mathrm{BF}_{4}$. Scan rate $0.1 \mathrm{~V} \mathrm{~s}^{-1}$. Standard error of $\Delta \mathrm{E}$ values $= \pm 5 \mathrm{mV}$.

By comparing the $K_{\text {red }} / K_{o x}$ ratios, or probably more clearer, from the $\Delta G_{r e d}-\Delta G_{o x}$ values derived $\left(\Delta G_{r e d}\right.$ and $\Delta G_{o x}$ refer to the free energies for the reactions of association of the ammonium salts with 1 and $1^{4+}$, respectively), it becomes quite evident that the neutral cavitand $\mathbf{1}$, shows a large preference over its oxidized form $\left(1^{4+}\right)$ for the encapsulation of the methyl ammonium salts $5^{+}-7^{+}\left(\Delta G_{\text {red }}-\Delta G_{o x}\right.$ values ranging from $\left.15-17 \mathrm{kcal} / \mathrm{mol}\right)$. For tetraethylammonium chloride, this energy difference is significantly lower $(8.6 \mathrm{kcal} / \mathrm{mol})$, probably as a consequence of the larger size of the salt, which makes that the differences between the encapsulation capabilities of the neutral and oxidized cavitand become less pronounced, both due to the lower affinity by $\mathbf{1}$ to complex with the larger salt, and for the relative higher tendency of $\mathbf{4}^{+}$to accommodate in the expanded oxidized form, $\mathbf{1}^{4+}$.

As an illustrative example, Figure 5 shows the voltammograms of 1 in the presence of increasing amounts of $4^{+}$, and the plot of the redox potential as a function of the concentration of $3^{+}-7^{+}$. Interestingly, the voltammetric titration of the cavitand 1 with increasing amounts of ammonium salts, allows the confirmation of the stoichiometry of the host:guest complexes by using the Method of Continuous Variations (MCV, also known as Job plot). ${ }^{[21]}$ For this purpose, we prepared a series of solutions of $\mathbf{1}$ and $\mathrm{NMe}_{4} \mathrm{Cl}$ in varying proportions, so that a complete range of mole ratios were sampled, while maintaining the total concentration, [1] + [NMe $\left.{ }_{4} \mathrm{Cl}\right]$, constant for each solution (see Figure 6 and Supplementary Information). This allowed us to determine that the maximum shift on $\Delta \mathrm{E}$ was achieved when the molar fraction is 0.5 , and therefore the stoichiometry of the aggregates is $1: 1$, confirming the results obtained by Mass Spectrometry and NMR spectroscopy.
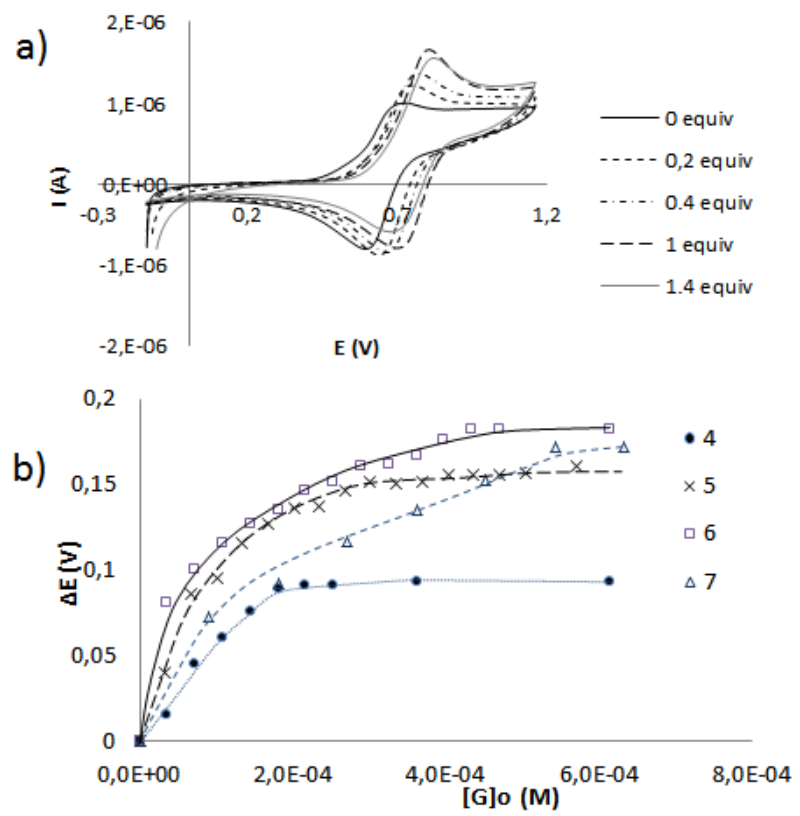

Figure 5. a) Cyclic voltammograms of 1 , with increasing amounts of $\mathrm{NEt}_{4} \mathrm{Cl}$ $\left[4^{+}\right]\left(\mathrm{Cl}^{-}\right)$. b) Plots of the $\Delta E$ values of 1 upon incremental amounts of $\left[4^{+}\right]\left(\mathrm{Cl}^{-}\right)$, $\left[5^{+}\right]\left(\mathrm{Cl}^{-}\right),\left[6^{+}\right]\left(\mathrm{Br}^{-}\right)$and $\left[7^{+}\right]\left(\mathrm{Cl}^{-}\right)$. The data were collected by taking the potentials at the maximum current values from the differential pulse voltammetry (DPV), using $0.2 \mathrm{mM}$ of compound 1 in $\mathrm{CHCl}_{3}$ in presence of $0.1 \mathrm{M} \mathrm{NBu}_{4} \mathrm{BF}_{4}$. The scan potential was initiated from $E_{\text {ocp }}$ to positive direction. Scan rate $0.1 \mathrm{~V} \mathrm{~s}^{-1}$. Ferrocene $\left(\mathrm{E}_{1 / 2}\left(\mathrm{Fc} / \mathrm{Fc}^{+}\right)=0.49 \mathrm{~V}\right)$ used as an internal standard.

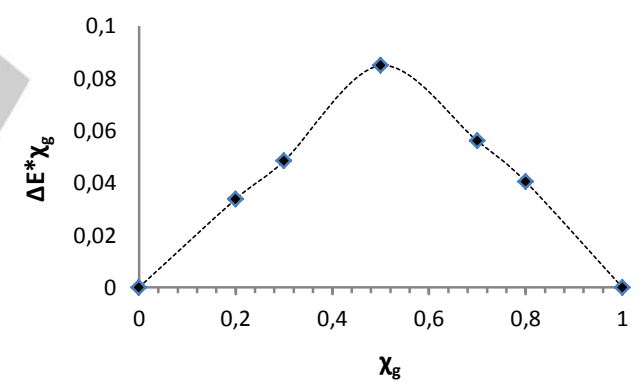

Figure 6: Job plot for the titration of 1 with $\mathrm{NMe}_{4} \mathrm{Cl}$ in $\mathrm{CH}_{2} \mathrm{Cl}_{2}$. The sum of the concentration of 1 and $\mathrm{NMe}_{4} \mathrm{Cl}$ was kept constant as [1] $\left[\mathrm{NMe}_{4} \mathrm{Cl}\right]=1.7 \mathrm{mM}$. Cyclic voltammetry data were collected in presence of $0.1 \mathrm{M} \mathrm{NBu}_{4} \mathrm{BF}_{4}$. $\mathrm{Xg}_{\mathrm{g}}$ is the guest molar fraction.

\section{Conclusions}

In summary, we described the preparation and full characterization of a tetraferrocenyl-resorcinarene cavitand. The presence of the ferrocenyl moieties introduces interesting features to the cavitand, both in terms of the redox-switchable encapsulation properties of the molecule, and in the possibility to use cyclic voltammetric studies to estimate the host-guest affinities. The molecule displays important redox-switchable structural changes, as indicated by the DFT analysis of its neutral and the related tetra-oxidized forms. The determination 
of the association constants between the tetraferrocenylcavitand and a series of ammonium salts were estimated by means of ${ }^{1} \mathrm{H}$ NMR spectroscopy. The large and positive $\Delta E$ shifts determined by electrochemical means, are a clear indication of the higher encapsulating capabilities of the neutral form of the cavitand compared to its oxidized form, and therefore indicates the clear redox-switchable trapping abilities of the host. The use of ESI mass spectrometry reveals two important features related to the nature of the encapsulation. First, it establishes that the host:guest stoichiometry is $1: 1$ and second, it reveals that the host-guest interaction is strong, as illustrated by the observation of a covalent $\mathrm{N}-\mathrm{C}$ bond breaking of the guest upon CID conditions. Our results demonstrate that single-stage ESI-MS and ESI tandem mass spectrometric techniques, display great potential to explore the intrinsic reactivity of guests in a confined space, beyond classical characterization purposes.

We believe that the results provided in this work may have broad implications for the design of switchable systems with predicted functionalities.

\section{Experimental Section}

General comments: All manipulations were carried out under nitrogen using standard Schlenk techniques and high vacuum. Anhydrous solvents were either distilled from appropriate drying agents (SPS) or purchased from Aldrich and degassed prior to use by purging with dry nitrogen and kept over molecular sieves. The octaamino-resorcinarene cavitand was obtained according to the literature procedure. ${ }^{[10]}$ All other reagents were used as received from commercial suppliers. NMR spectra were recorded on Varian spectrometers operating at 300 or 500 $\mathrm{MHz}\left({ }^{1} \mathrm{H} \mathrm{NMR}\right)$ and 75 and $125 \mathrm{MHz}\left({ }^{13} \mathrm{C} \mathrm{NMR}\right)$, respectively. NMR spectra were recorded at room temperature with $\mathrm{C}_{6} \mathrm{D}_{6}$ or Toluene- $d_{8}$ as solvents. DOSY experiments were collected with the standard DgcsteSL (DOSY Gradient Compensated Stimulated Echo with Spin Lock) sequence. The diffusion parameters were optimized to obtain a $90-95 \%$ on signal-intensity decay. Typical values are diffusion times $(\Delta)$ of $80 \mathrm{~ms}$, with encoding gradient pulses of total duration $(\delta)$ of $2 \mathrm{~ms}$. Data were acquired non-spinning with an array of 15 gradient amplitudes with 16 scans per value in a interleaved fashion using a block size of 8 scans. Diffusion coefficients were calculated by using the values of the intensity of the observed signal from the Stejskal-Tanner equation ${ }^{[22]}$ with DOSY macro available in the Varian NMRJ2.2c software.

A Q-TOF Premier (Waters) mass spectrometer with an electrospray source operating in the V-mode was used. The drying gas as well as the cone gas was nitrogen at a flow of $300 \mathrm{Lh}^{-1}$ and $30 \mathrm{Lh}^{-1}$, respectively. The temperature of the source block was set to $100^{\circ} \mathrm{C}$ and the desolvation temperature was set to $150^{\circ} \mathrm{C}$. A capillary voltage of $3.5 \mathrm{kV}$ oe $3.3 \mathrm{kV}$ was used in the positive or negative scan mode, respectively and the cone voltage was adjusted typically to $U_{c}=50 \mathrm{~V}$. Mass calibration was performed by using Nal solutions in isopropanol:water (1:1) from m/z 50 3000 . For the determination of the molecular composition of the supramolecular adducts of 1 with different guests $3^{+}-7^{+}$and 8 , to a $5 \times$ $10^{-4} \mathrm{M}$ solution of 1 in $\mathrm{CHCl}_{3}: \mathrm{CH}_{3} \mathrm{OH}(1: 1)$ was added an equimolar amount of the $3^{+}-7^{+}$and 8 guests and analyzed by negative and positive ESI-MS. Both positive and negative ESI mass spectra displayed very useful information about the stoichiometry of the supramolecular recognition on the basis of the $\mathrm{m} / \mathrm{z}$ values and comparison between the observed and the theoretical isotopic pattern of the identified species. In this sense, the chemical composition determination of each species containing $4 \mathrm{Fe}$ metal centers was facilitated by the characteristic isotopic pattern at natural abundance of $\mathrm{Fe}$. The chemical composition of each peak was assigned by comparison of the isotope experimental and theoretical patterns, considering natural abundance for all elements, using the MassLynx 4.1 program. For collision induced dissociation (CID) experiments, the complete isotopic envelope of the species of interest was mass-selected with the first quadrupole (isolation width ca. $4 \mathrm{Da}$ ), interacted with argon in the T-wave collision cell while analyzing the ionic fragments with the TOF analyzer. The collision energy was systematically stepped in the $E_{l a b}=15-30 \mathrm{eV}$ range. Validation of the proposed fragmentation scheme was provided by "in-source" generation of the desired intermediates and subsequent CID investigation. For this purpose, higher cone voltages (typically Uc $=90-100 \mathrm{~V}$ ) were used

$\mathrm{E}_{1 / 2}(\mathrm{Epa})$ versus $\mathrm{Fc}^{+} / \mathrm{Fc}$ was estimated by cyclic voltammetry method using platinum disc electrode as a working electrode, platinum wire as a counter electrode, and SCE as a reference electrode; the solution $(0.2$ $\mathrm{mM}$ ) was dissolved in $\mathrm{CH}_{2} \mathrm{Cl}_{2}$ using $0.1 \mathrm{M} \mathrm{NBu}_{4} \mathrm{BF}_{4}$ as a supporting electrolyte with a scan rate of $50 \mathrm{mV} \mathrm{s}^{-1}$ and all the potentials were calibrated and referenced with ferrocene $\left(\mathrm{E}_{1 / 2}\left(\mathrm{Fc} / \mathrm{Fc}^{+}\right)=0.49 \mathrm{~V}\right.$ vs SCE$)$ as an internal standard.

Synthesis and characterization resorcinarene-tetraferrocenyl-based cavitand (compound 1). A mixture of resorcinarene-octaamino-based cavitand ${ }^{[10]}(211.7 \mathrm{mg}, 0.139 \mathrm{mmol})$ ferrocene-carboxaldehyde (119.84 $\mathrm{mg}, 0.56 \mathrm{mmol})$ in a mixed of $\mathrm{CH}_{2} \mathrm{Cl}_{2}: \mathrm{CH}_{3} \mathrm{OH}(15: 10 \mathrm{~mL})$ was stirred at $65^{\circ} \mathrm{C}$ for $24 \mathrm{~h}$. The final suspension was cooled to room temperature and solvent were remove. Then, acetonitrile $(10 \mathrm{~mL})$ was added and stirred at room temperature for $1 \mathrm{~h}$. The resulting brown precipitate was collected by filtration. The crude product was eluted in a column chromatography of silica gel with dichloromethane: acetone (9:1) to give compound 1 as a red solid. Yield: $208 \mathrm{mg}(65 \%) .{ }^{1} \mathrm{H}$ NMR $\left(500 \mathrm{MHz}, \mathrm{C}_{6} \mathrm{D}_{6}\right) \delta 7.81$ (s, 8H, $\left.\mathrm{CH}_{\mathrm{Ph}}\right), 7.70\left(\mathrm{~s}, 4 \mathrm{H}, \mathrm{CH}_{\mathrm{Ph}}\right), 7.57\left(\mathrm{~s}, 4 \mathrm{H}, \mathrm{CH}_{\mathrm{Ph}}\right), 6.44(\mathrm{t}, \mathrm{J}=8.2 \mathrm{~Hz}, 4 \mathrm{H}, \mathrm{CH})$, 5.09 (s, 4H, CH $\left.H_{\mathrm{fc}}\right), 4.17\left(\mathrm{~s}, 12 \mathrm{H}, \mathrm{CH}_{\mathrm{fc}}\right), 3.89\left(\mathrm{~s}, 20 \mathrm{H}, \mathrm{CH}_{\mathrm{fc}}\right), 2.55(\mathrm{~s}, 8 \mathrm{H}$, $\left.\mathrm{CH}_{2}\right), 1.64\left(\mathrm{~s}, 8, \mathrm{CH}_{2}\right), 1.56\left(\mathrm{~d}, J=58.8 \mathrm{~Hz}, 56 \mathrm{H}, \mathrm{CH}_{2}\right), 0.99(\mathrm{t}, J=6.3 \mathrm{~Hz}$, $\left.12 \mathrm{H}, \mathrm{CH}_{3}\right) \cdot{ }^{13} \mathrm{C}$ NMR $\left(75 \mathrm{MHz}, \mathrm{C}_{6} \mathrm{D}_{6}\right) \delta 181.6(\mathrm{NCN}), 156.7\left(\mathrm{C}_{\mathrm{ph}}\right), 149.7$ $\left(\mathrm{C}_{\mathrm{ph}}\right), 135.7\left(\mathrm{C}_{\mathrm{ph}}\right), 117.6\left(\mathrm{C}_{\mathrm{ph}}\right), 69.7\left(\mathrm{C}_{\mathrm{fc}}\right), 67.7\left(\mathrm{C}_{\mathrm{fc}}\right), 33.8\left(\mathrm{CH}_{2}\right), 32.9\left(\mathrm{CH}_{2}\right)$, $32.0\left(\mathrm{CH}_{2}\right), 29.8\left(\mathrm{CH}_{2}\right), \quad 29.5\left(\mathrm{CH}_{2}\right), 28.4\left(\mathrm{CH}_{2}\right), 22.8\left(\mathrm{CH}_{2}\right), \quad 18.3\left(\mathrm{CH}_{2}\right)$, 14.0 $\left(\mathrm{CH}_{2}\right)$, $1.0\left(\mathrm{CH}_{3}\right)$. Anal.Calcd for $\mathrm{C}_{140} \mathrm{H}_{152} \mathrm{O}_{8} \mathrm{~N}_{8} \mathrm{Fe}_{4}\left(4 \mathrm{H}_{2} \mathrm{O}\right)$ (2369.9587): C, 70.94; H, 6.80; N, 4.73. Found: C, 71.21; H, 7.40; N, 4.8. ESI-TOF-MS (positive mode): $[\mathrm{M}+3 \mathrm{H}]^{3+}(\mathrm{m} / \mathrm{z} 767.0),[\mathrm{M}+2 \mathrm{H}]^{2+}(\mathrm{m} / \mathrm{z}$ 1149.9); $[\mathrm{M}+\mathrm{H}]^{+}(\mathrm{m} / \mathrm{z} 2298.9)$.

Study of guest inclusion phenomena by ${ }^{1} \mathbf{H}$ NMR spectra. The determination of binding constants by means of ${ }^{1} \mathrm{H}$ NMR was carried in different solvents: A solution of compound 1 in $\mathrm{C}_{6} \mathrm{D}_{6}$ was prepared and 1 and 2 equiv. of guests were added at room temperature in an NMR tube, and then ${ }^{1} \mathrm{H}$ NMR spectrum was acquired. Integration of the bound and free peaks corresponding to suitable host protons gave the equilibrium concentrations of bound and free host, from which the binding constant $K$ could be determined. The same experiment was done in toluene- $d_{8}$ and DMSO- $d_{6}$ using some of the proposed guest.

Computational Details. Density functional theory (DFT) calculations were performed with the CP2K code ${ }^{[23]}$ and based on the PBE exchangecorrelation functional, ${ }^{[24]}$ supplemented by a correction for dispersion interactions (D3). ${ }^{[25]}$ The Quickstep ${ }^{[26]}$ algorithm was used to solve the electronic structure problem using a double-zeta plus polarization $(\mathrm{DZVP})^{[27]}$ basis set to represent valence orbitals and plane waves for the electron density (300 Ry cutoff). Valence-core interactions were treated by means of GTH-type pseudopotentials. ${ }^{[28]}$ Wave function optimization was achieved through an orbital transformation method. ${ }^{[29]}$ Models were treated as isolated in a cubic box of $34 \AA$ edge and optimized until gradients were $<5 \cdot 10^{-4}$ a.u. Restricted calculations were performed for 
the $\mathrm{Fe}(\mathrm{II})$ cavitand (corresponding the the siglet state of the ferrocene moiety), whereas an unrestricted formalism was used for the $\mathrm{Fe}$ (III) cavitand (quintet state, assuming a doublet state for each ferrocenium moiety). Spin distribution in the $\mathrm{Fe}$ (III) cavitand (optimized open conformation) were consistent with a doublet state for each ferrocenium moiety, with small delocalizations on the aromatic rings. Atomic Mulliken spin moments, summed on a per-residue basis, turned to be the followings: resorcinarene +0.02 ; linkers 0.23 (each); chlorides $(0.11$ each); ferrocenium 0.63 each (Fe 0.76 each). Solvent effects (toluene) were included by means of single point calculation with the SMD method $^{[30]}$ as implemented in Gaussian09; ${ }^{[31]}$ calculations were performed at M06 level with 6-31g(d,p) basis set for $\mathrm{N}, \mathrm{C}, \mathrm{O}$ and $\mathrm{H}^{\left[{ }^{[32]}\right.}$ along with the $\mathrm{SDD}^{[33]}$ pseudopotential and its associated basis set for $\mathrm{Fe}$ including an f orbital (exp. 2.462). ${ }^{[34]}$

\section{Acknowledgements}

We gratefully acknowledge financial support from MEC of Spain (CTQ2014-51999-P and CTQ2014-54071-P) and the Universitat Jaume I (P11B2014-02). We are grateful to the Serveis Centrals d'Instrumentació Científica (SCIC) of the Universitat Jaume I for providing with spectroscopic facilities. We would also like to thank the Generalitat Valenciana for a fellowship (S-R.-B.).

Keywords: cavitands • resorcinarene $\bullet$ ferrocene $\bullet$ ammonium, encapsulation $\cdot$ host-guest

[1] a) J. Lagona, P. Mukhopadhyay, S. Chakrabarti, L. Isaacs, Angew. Chem. Int. Ed. 2005, 44, 4844-4870; b) P. D. Beer, Advances in Inorganic Chemistry 1992, 39, 79-157; c) I. Pochorovski, F. Diederich, Acc. Chem. Res. 2014, 47, 2096-2105; d) D. Ajami, J. Rebek, Jr., Acc. Chem. Res. 2013, 46, 990-999; e) P. D. Frischmann, M. J. MacLachlan, Chem. Soc Rev. 2013, 42, 871-890; f) P. Ballester, A. Vidal-Ferran, P. W. N. M. van Leeuwen, in Advances in Catalysis, Vol 54, Vol. 54 (Eds.: B. C. Gates, H. Knozinger), 2011, pp. 63-126; g) Z. Laughrey, B. C. Gibb, Chem. Soc. Rev. 2011, 40, 363-386; h) L. Pirondini, E. Dalcanale, Chem. Soc. Rev. 2007, 36, 695-706; i) S. J. Rowan, S. J. Cantrill, G. R. L. Cousins, J. K. M. Sanders, J. F. Stoddart, Angew. Chem. Int. Ed. 2002, 41, 898-952; j) J. Yoon, S. K. Kim, N. J. Singh, K. S. Kim, Chem. Soc. Rev. 2006, 35, 355360.

[2] a) D. J. Cram, J. M. Cram, J. F. Stoddart, Container Molecules and Their Guests, The Royal Society of Chemistry, London, 1994; b) L. C. Palmer, J. Rebek, Org. Bio. Chem. 2004, 2, 3051-3059; c) L. Trembleau, J. Rebek, Science 2003, 301, 1219-1220; d) D. M. Rudkevich, J. Rebek, Eur. J. Org. Chem. 1999, 1991-2005

[3] P. D. Frischmann, M. J. Maclachlan, Comments Inorganic Chem. 2008, 29, 26-45.

[4] A. K.-W. Chan, W. H. Lam, Y. Tanaka, K. M.-C. Wong, V. W.-W. Yam, Proc Natl. Acad. Sci. U. S. A. 2015, 112, 690-695.

[5] a) I. Pochorovski, J. Milic, D. Kolarski, C. Gropp, W. B. Schweizer, F. Diederich, J. Am. Chem. Soc. 2014, 136, 3852-3858; b) I. Pochorovski, M.-O. Ebert, J.-P. Gisselbrecht, C. Boudon, W. B. Schweizer, F. Diederich, J. Am. Chem. Soc. 2012, 134, 14702-14705; c) I. Pochorovski, C. Boudon, J.-P. Gisselbrecht, M.-O. Ebert, W. B. Schweizer, F. Diederich, Angew. Chem. Int. Ed. 2012, 51, 262-266; d) M. H. Dueker, F. Kutter, T. Duelcks, V. A. Azov, Supramolecular Chemistry 2014, 26, 552-560; e) M. Frei, F. Diederich, R. Tremont, T. Rodriguez, L. Echegoyen, Helv. Chim. Acta 2006, 89, 2040-2057.

[6] G. A. Evtugyn, E. E. Stoikova, R. V. Shamagsumova, Russian Chemical Reviews 2010, 79, 1071-1097.
[7] P. D. Beer, A. D. Keefe, M. G. B. Drew, J. Organomet. Chem. 1988, 353, C10-C12.

[8] a) P. D. Beer, A. D. Keefe, V. Bohmer, H. Goldmann, W. Vogt, S. Lecocq M. Perrin, J. Organomet. Chem. 1991, 421, 265-273; b) P. D. Beer, E. J. Hayes, Coord. Chem. Rev. 2003, 240, 167-189; c) B. Tomapatanaget, T. Tuntulani, Tetrahedron Lett. 2001, 42, 8105-8109; d) I. Dumazet, P. D. Beer, Tetrahedron Lett. 1999, 40, 785-788; e) P. D. Beer, Z. Chen, M. G. B. Drew, P. A. Gale, J. Chem. Soc.-Chem. Commun. 1995, 1851-1852; f P. D. Beer, Z. Chen, A. J. Goulden, A. Graydon, S. E. Stokes, T. Wear, J. Chem. Soc.-Chem. Commun. 1993, 1834-1836; g) P. D. Beer, E. L. Tite A. Ibbotson, J. Chem. Soc.-Dalton Trans. 1991, 1691-1698; h) B. Tomapatanaget, T. Tuntulani, O. Chailapakul, Org. Lett. 2003, 5, 1539 1542; i) C. R. Bondy, S. J. Loeb, Coord. Chem. Rev. 2003, 240, 77-99; j) M. I. R. Valderrama, R. A. V. Garcia, T. Klimova, E. Klimova, L. OrtizFrade, M. M. Garcia, Inorg. Chim. Acta 2008, 361, 1597-1605; k) J. Han, Y. H. Cai, L. Liu, C. G. Yan, Q. Li, Tetrahedron 2007, 63, 2275-2282; I) R. Sharma, R. Margani, S. M. Mobin, R. Misra, Rsc Advances 2013, 3, 5785 5788; m) A. J. Evans, S. E. Matthews, A. R. Cowley, P. D. Beer, Dalton Trans. 2003, 4644-4650.

[9] a) H. J. Choi, Y. S. Park, J. Song, S. J. Youn, H. S. Kim, S. H. Kim, K. Koh, K. Paek, J. Org. Chem. 2005, 70, 5974-5981; b) B. B. Adhikari, A. Fujii, M. P. Schramm, Eur. J. Org. Chem. 2014, 2014, 2972-2979; c) A. R. Far, A. Shivanyuk, J. Rebek, J. Am. Chem. Soc. 2002, 124, 2854-2855; d) M. P. Schramm, R. J. Hooley, J. Rebek, Jr., J. Am. Chem. Soc. 2007, 129, 9773-9779; e) K. Kobayashi, M. Yamanaka, Chem. Soc. Rev. 2015, 44 449-466.

[10] a) K.-D. Zhang, D. Ajami, J. Rebek, J. Am. Chem. Soc. 2013, 135, 1806418066; b) F. Hof, L. Trembleau, E. C. Ullrich, J. Rebek, Angew. Chem. Int. Ed. 2003, 42, 3150-3153; c) B. W. Purse, A. Gissot, J. Rebek, J. Am Chem. Soc. 2005, 127, 11222-11223.

[11] J. R. Moran, J. L. Ericson, E. Dalcanale, J. A. Bryant, C. B. Knobler, D. J Cram, J. Am. Chem. Soc. 1991, 113, 5707-5714.

[12] a) A. Macchioni, G. Ciancaleoni, C. Zuccaccia, D. Zuccaccia, Chem. Soc Rev. 2008, 37, 479-489; b) Y. Cohen, L. Avram, L. Frish, Angew. Chem. Int. Ed. 2005, 44, 520-554; c) L. Avram, Y. Cohen, Chem. Soc. Rev. 2015, 44, 586-602

[13] M. Kvasnica, B. W. Purse, New J. Chem. 2010, 34, 1097-1099.

[14] a) N. K. Beyeh, M. Goeth, L. Kaufmann, C. A. Schalley, K. Rissanen, Eur. J. Org. Chem. 2014, 2014, 80-85; b) N. K. Beyeh, D. P. Weimann, L. Kaufmann, C. A. Schalley, K. Rissanen, Chem. Eur. J. 2012, 18, $5552-$ 5557 ; c) H. Mansikkamaki, C. A. Schalley, M. Nissinen, K. Rissanen, New J. Chem. 2005, 29, 116-127.

[15] Z. Qi, T. Heinrich, S. Moorthy, C. A. Schalley, Chem. Soc. Rev. 2015, 44, 515-531.

[16] T. Mitkina, V. Fedin, R. Llusar, I. Sorribes, C. Vicent, J. Am. Soc. Mass Spectrom. 2007, 18, 1863-1872.

[17] H. Zhang, M. Grabenauer, M. T. Bowers, D. V. Dearden, J. Phys. Chem. A 2009, 113, 1508-1517.

[18] T.-C. Lee, E. Kalenius, A. I. Lazar, K. I. Assaf, N. Kuhnert, C. H. Grun, J. Janis, O. A. Scherman, W. M. Nau, Nat. Chem. 2013, 5, 376-382.

[19] a) M. Schafer, Angew. Chem. Int. Ed. 2003, 42, 1896-1899; b) R. R. Julian, J. A. May, B. M. Stoltz, J. L. Beauchamp, Angew. Chem. Int. Ed. 2003, 42, 1012-1015.

[20] a) E. Laviron, L. Roullier, J. Electroanal. Chem. 1985, 186, 1-15; b) D Sobransingh, M. B. Dewal, J. Hiller, M. D. Smith, L. S. Shimizu, New J. Chem. 2008, 32, 24-27.

[21] a) J. S. Renny, L. L. Tomasevich, E. H. Tallmadge, D. B. Collum, Angew. Chem. Int. Ed. 2013, 52, 11998-12013; b) L. Fielding, Tetrahedron 2000 56, 6151-6170; c) V. M. S. Gil, N. C. Oliveira, J. Chem. Educ. 1990, 67, 473-478; d) P. Job, Annales De Chimie France 1928, 9, 113-203.

[22] E. O. Stejskal, J. E. Tanner, J. Chem. Phys. 1965, 42, 288-292.

[23] J. VandeVondele, M. Krack, F. Mohamed, M. Parrinello, T. Chassaing, J. Hutter, Comput. Phys. Commun. 2005, 167, 103-128.

[24] J. P. Perdew, K. Burke, M. Ernzerhof, Phys. Rev. Lett. 1996, 77, 38653868. 
[25] S. Grimme, J. Antony, S. Ehrlich, H. Krieg, J. Chem. Phys. 2010, 132 [26] G. Lippert, J. Hutter, M. Parrinello, Mol. Phys. 1997, 92, 477-487.

[27] J. VandeVondele, J. Hutter, J. Chem. Phys. 2007, 127.

[28] a) S. Goedecker, M. Teter, J. Hutter, Phys. Rev. B 1996, 54, 1703-1710; b) C. Hartwigsen, S. Goedecker, J. Hutter, Phys. Rev. B 1998, 58, 3641 3662; c) M. Krack, Theor. Chem. Acc. 2005, 114, 145-152.

[29] J. VandeVondele, J. Hutter, J. Chem. Phys. 2003, 118, 4365-4369.

[30] A. V. Marenich, C. J. Cramer, D. G. Truhlar, J. Phys. Chem. B 2009, 113 , 6378-6396.

[31] M. J. Frisch, G. W. Trucks, H. B. Schlegel, G. E. Scuseria, M. A. Robb, J. R. Cheeseman, G. Scalmani, V. Barone, B. Mennucci, G. A. Petersson, H. Nakatsuji, M. Caricato, X. Li, H. P. Hratchian, A. F. Izmaylov, J. Bloino, G. Zheng, J. L. Sonnenberg, M. Hada, M. Ehara, K. Toyota, R. Fukuda, J. Hasegawa, M. Ishida, T. Nakajima, Y. Honda, O. Kitao, H. Nakai, T. Vreven, J. A. Montgomery Jr., J. E. Peralta, F. Ogliaro, M. Bearpark, J. J. Heyd, E. Brothers, K. N. Kudin, V. N. Staroverov, R. Kobayashi, J. Normand, K. Raghavachari, A. Rendell, J. C. Burant, S. S. lyengar, J.
Tomasi, M. Cossi, N. Rega, J. M. Millam, M. Klene, J. E. Knox, J. B. Cross, V. Bakken, C. Adamo, J. Jaramillo, R. Gomperts, R. E. Stratmann O. Yazyev, A. J. Austin, R. Cammi, C. Pomelli, J. W. Ochterski, R. L. Martin, K. Morokuma, V. G. Zakrzewski, G. A. Voth, P. Salvador, J. J. Dannenberg, S. Dapprich, A. D. Daniels, Ö. Farkas, J. B. Foresman, J. V. Ortiz, J. Cioslowski, D. J. Fox, Gaussian 09, Revision, Gaussian, Inc., Wallinford, CT, 2009

[32] M. M. Francl, W. J. Pietro, W. J. Hehre, J. S. Binkley, M. S. Gordon, D. J. Defrees, J. A. Pople, J. Chem. Phys. 1982, 77, 3654-3665.

[33] D. Andrae, U. Haussermann, M. Dolg, H. Stoll, H. Preuss, Theor. Chim. Acta 1990, 77, 123-141.

[34] A. W. Ehlers, M. Bohme, S. Dapprich, A. Gobbi, A. Hollwarth, V. Jonas, K. F. Kohler, R. Stegmann, A. Veldkamp, G. Frenking, Chem. Phys. Lett. 1993, 208, 111-114. 
Entry for the Table of Contents (Please choose one layout)

\section{FULL PAPER}

A redox-switchable resorcinarenebased cavitand with four ferrocenyls at the rim has been obtained. The molecule allows the reversible encapsulation of a series of ammonium salts.

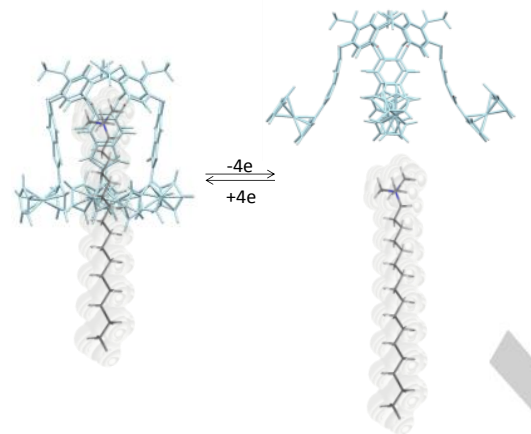

Sheila Ruiz-Botella, Pietro Vidossich, Gregori Ujaque, ${ }^{*}$ Cristian Vicent ${ }^{\star}$ and Eduardo Peris*

Page No. - Page No.

A tetraferrocenyl-resorcinarene cavitand as redox-switchable host of ammonium salts 